\title{
Stunting and Anemia in Infants Among Breastfeeding Mothers in Binjai City
}

\author{
Etti Sudaryati ${ }^{1}$, Ernawati Nasution ${ }^{2}$, Ida Yustina ${ }^{3}$ \\ ${ }^{1,2}$ Department of Public Health Nutrition, University of Sumatera Utara, Indonesia \\ etysudaryatiegmail.com \\ ernawati@usu.ac.id \\ ${ }^{3}$ Department of Administration and Health Policy, University of Sumatera Utara, Indonesia \\ idayusteyahoo.com
}

\begin{abstract}
Anemia and stunting are major public health problems, and they have a high prevalence rate in Southeast Asia. In this cross-sectional study, infants from 0 to 6 months and their mothers were investigated to determine the prevalence of stunting and anemia in infants and anemia in breastfeeding mothers. Multistage cluster was used as sampling techniquein selecting five sub districtsin Binjai City of North Sumatera Province, Indonesia. Analysis uses the information of hemoglobin levels from 100 breastfeeding infants and their mothers which have their peripheral blood tested by hemocue. Examination of anemia infants based on the levels of hemoglobin give results $<14 \mathrm{~g} / \mathrm{dL}$ for $0-3$ days of age, $<13 \mathrm{~g} / \mathrm{dL}$ for one weekof age, $<12 \mathrm{~g} / \mathrm{dLf}$ or 2 weeks of age, $<11 \mathrm{~g} / \mathrm{dL}$ for 1 month of age, $<10 \mathrm{~g} / \mathrm{dL}$ for $2-6$ monthsof age. Anthropometric indicator (range-for-age $\leq 2 \mathrm{SD}$ ) were measured for stunting infants. Data analysis uses chi-square test. The overall prevalence of anemia in infants was $29 \%$, and anemia in breastfeeding mothers was $52 \%$, while prevalence of stunting in infants was $34 \%$. Anemia in breastfeeding mothers is not associated with infant anemia $(\mathrm{p}=0.685>0.05)$, and with stunting in infant $(p=0.161>0.05)$. Hb concentration in infants were not statistically different $(\mathrm{p}=\mathbf{0 . 8 3})$ among breastfeeding mothers which are anemia $(11.4 \pm 1.7 \mathrm{~g} / \mathrm{dL})$ and non anemia $(11.5 \pm 2.2 \mathrm{~g} / \mathrm{dL})$. The results of this study indicate that maternal anemia during breastfeeding was not associated with anemia and stunting in infants. These results are very important as a baseline for prevention planning of stunting and anemia in children.
\end{abstract}

Keywords — Stunting, anemia, breastfeeding, infant.

\section{INTRODUCTION}

Anemia and stunting in infants and breastfeeding are the global targets to improve nutrition of first thousand days of life to the children. The decrease of stunting by up to $40 \%$ is the first global target. The second global target is $50 \%$ reduction of anemia in non pregnant women in reproductive age. The third global target is $50 \%$ reduction of low birth weight ( $<2500$ grams). The fourth global target is $0 \%$ increase of overweight prevalence in children under five years old. the fifth global target is the increase of exclusive breastfeeding to at least $50 \%$ in the first six months of life [1].
Anemia and malnutrition in children, have an adverse impact on human of cycle life, which gives serious implications for individuals and society. This situation contributes significantly to morbidity and mortality of children under 5 years of age and becomes a major public health problem, particularly in developing countries [2]. As in Philippines, the prevalence of stunting and iron deficiency werepersistently high in young children. The prevalence of anemia in children under 2 years of age are still high and difficult to be subtracted, marked the high anemia among older children and pregnant and lactating women [3] In China found that 54.3\% of 6-11 month old infants in poor rural are anemic, and $24.3 \%$ infants suffer from moderate or severe anemia [4].

Anemia and iron deficiency are associated with a lower physical capacity and increased susceptibility to infections, need to be tackled before women become pregnant in order to reduce the risks of poor maternal health and low birth weight babies. Meanwhile, in Brazil reduction of stunting has been associated to improved educational levels of mothers; increased purchasing power of low-income families; expanded public water and sewage systems; and virtual universalization of basic health care, including prenatal care [1].

Indonesia as developing country which has a complex issues, especially the issue of nutrition. Stunting and anemia are the issues of concern that need completion. The completion of the nutrition problem has not declined significantly until today, but increasing. Stunting as a problem related to the growth in children shows very real effect on the cognitive, as well as anemia. The proportion of 
children under 5 years of age which were stunted is $37 \%$, with levels of $50 \%$ in some regions (according to the report of Riskesdas 2013 [5].

Approximately 9.2 million (37\%) children under 5 years of age are stunted of the 24.5 million in Indonesia. Children of undernutrition have an increased risk of mortality, illness and infections, delayed development, cognitive deficits, poorer school performance, and fewer years in school. The mortality rate for children under 5 years of age is 40 per 1,000 live births, and nearly $45 \%$ of these child deaths are attributable to various forms of undernutrition [6].

According to data from the Riskesdas 2013, more than a quarter of children under 5 years of age and $37 \%$ of pregnant women are anemic [5]. The anemic children were at higher risk for stunting $(\mathrm{OR}=1.37)$ [7]. Iron deficiency anemia in the first years of life has been related to many adverse consequences. In the short term, infants with iron deficiency anemia are at higher risk of cognitive, social and emotional delays [4]. However, when the food was not enough in this pregnancy period, breastfeeding is not good, and complementary foods are not appropriate, all of these were responsible in the incidence of stunting and infant morbidity, including nutritional anemia. The first 6 months of life are very important in giving exclusive breastfeeding because breast milk is enough to support the growth of the child to be normal. Then the children can be given complementary foods and lactating continued until 24 months [8].

Study in China, has found that children still breastfed over 6 months of age had lower $\mathrm{Hb}$ concentrations and higher anemia prevalence than their non-breastfeeding counterparts, and that children who had ever been formula-fed had significantly higher $\mathrm{Hb}$ concentrations and lower anemia prevalence than their non-formula-fed counterparts. The results suggest the importance of iron supplementation or home fortification while breastfeeding [4]. The presence of iron deficiency anemia in infants in southern Israel is inversely affected by the level of maternal knowledge of anemia and adherence to iron supplementation [9].

The present study used the data collected during the field investigation are anthropometric indicators and hemoglobin levels, in order to assess stunting and anemia in infant and anemia in breastfeeding mother in Binjai City, Province of Sumatera Utara, Indonesia. This paper describes the focus of attention on the part of the first thousand days of life and the problems that exist in it concerning the mother and child. The data obtained from this research is very important as information to address the problem of stunting and anemia in children through breastfeeding. This study gives thought to continually improve maternal and child health because it became important as a basic investment in human resources in the future. In addition, the results of this study provide information in planning the policy of community nutrition in improving nutrition period of the first 1000 days of a child's life, one of which policy to improve breastfeeding.

\section{METHODS}

Data are taken from a cross-sectional study in Binjai City in 2016. Data were collected from 100 households who have breastfeeding mothers and their 0-6 months of age babies. The sample was selected in a multistage cluster with two processes. First, the blocks (sub districts) were selected from a cluster of districts by simple random sampling. The clusters are numbered five districts. A total of $10 \mathrm{sub}$ districts were selected at this stage, from 37 sub districts. In the second stage, a fixed number of 10 households were selected in each selected sub districts. Collected data are the characteristics of the mother and their babies.

The respondents were given an explanation of the research objectives and benefits of the research, then respondents signed informed consent. Hemoglobin measurements were taken in the field using the Hemocue digital. A drop of capillary blood was taken from the finger (or from the heel in the case of infants 0-6 months) and drawn in one continuous process directly into a reagent-coated microcuvette and the filled microcuvette was inserted into a cuvette holder of a portable, battery-operated photometer, the hemoglobin levels will be seen on the screen of hemocue. Cuvettes that have been used cannot be reusable and should be discarded. Hemoglobin concentration was indicated on a digital readout in grams per deciliter. Examination of anemia infant based on the levels of hemoglobin $<14 \mathrm{~g} / \mathrm{dL}$ for $0-3$ days of age, $<13 \mathrm{~g} / \mathrm{dLf}$ for one week 
of age, $<12 \mathrm{~g} / \mathrm{dLf}$ for 2 week of age, <11g/dLfor 1 month of age, $<10 \mathrm{~g} / \mathrm{dL}$ for $2-6$ months of age. Breastfeeding mother as anemia with hemoglobin level $<12 \mathrm{~g} / \mathrm{dL}$.

Measurements of current length were collected by appropriately trained student from department of public health nutrition following World Health Organization (WHO) recommendations. Horizontal length was measured with infantometer in up to 0.1 $\mathrm{cm}$ accuracy. We computed Z-scores height-for-age by sex (HAZ). Recumbent spine length was measured according to standardized procedures and height-for-age (HAZ) $z$-scores were calculated. If $<-2$ SD HAZ of the World Health Organization's 2006 Growth Standards will be considered stunting. Using computerize software, a chi-square test were performed to determine the relationships between anemia in breastfeeding mothers and anemia and stunting in infant. Association were considered as statistically significant at values $\mathrm{P}<0.05$.

\section{A. Ethical Considerations}

The study was granted ethical approval from the Ethics Committee of the Faculty of Nursing, University of Sumatera Utara. Prior to the first interviewed women were informed about the objective of the study and provided informed consent. Arrangements were made for the study to pay all health related expenses of the mothers and children participating in the study.

\section{RESULTS}

In this study, as showed in Table 1, breastfeeding mothers age is obtained mostly of $20-30$ years $(78 \%)$ and a maternal education are mostly at the medium school level (67\%). The family income above the regional minimum wage $\mathrm{Rp} 1,700,000.00$ is only $42 \%$.

TABLE I

MATERNAL CHARACTERISTICS

\begin{tabular}{|l|r|r|}
\hline \multirow{2}{*}{ Maternal Characteristics } & \multicolumn{2}{|c|}{ Number } \\
\cline { 2 - 3 } & $\mathrm{n}$ & $\%$ \\
\hline Age : - <20 & 5 & 5.0 \\
$-20-30$ & 78 & 78.0 \\
$-30-40$ & 17 & 17.0 \\
\hline Education : -basic/low & 25 & 25.0 \\
-medium & 67 & 67.0 \\
-high & 8 & 8.0 \\
\hline
\end{tabular}

\section{A. Anemia in breastfeeding mothers and their infants}

The average $\mathrm{Hb}$ concentration in breastfeeding mothers from 100 maternal blood samples examined were $11.895 \pm 1.546$ (mean \pm sd). Overall, with a view cut off $\mathrm{Hb}$ concentration $<12 \mathrm{gr} / \mathrm{dl}$ in mother is called anemia, then the prevalence of anemia in breastfeeding mother was $52 \%$, and non anemia was $48 \%$. The infants ranged in age from 0 to 6 months of age, from 100 samples of blood in infant among which are anemic as many as $29 \%$. The average $\mathrm{Hb}$ concentration in infants were $11.464 \pm 1.952$ (mean $\pm \mathrm{sd}$ ). The average $\mathrm{Hb}$ concentration in mother with infants age group 0-6 months of age can be seen in Table 2.

The average concentration of hemoglobin in infants of breastfeeding mothers whose anemia was $11.4 \pm 1.7 \mathrm{~g} / \mathrm{dl}$, and in infants of breastfeeding mothers whose non anemia was $11.5 \pm 2.2 \mathrm{~g} / \mathrm{dl}$. Results of $t$ test were not different ( $\mathrm{p}=0.83$ ) about infants' $\mathrm{Hb}$ concentration among breastfeeding mothers are anemia and mothers of non anemia.

The average infant $\mathrm{Hb}$ concentration correlated with their age $(\mathrm{p}=0.001)$, in which the hemoglobin concentration in newborns decreased in the following month, then stable for 1-3 months of a baby's life, and decreased when the baby is 4-6 months old.

TABLE II

HB CONCENTRATION IN BREASTFEEDING MOTHERS WITH INFANTS AGE GROUP 0-6 MONTHS

\begin{tabular}{|c|r|r|r|r|r|}
\hline \multirow{2}{*}{$\begin{array}{l}\text { Age } \\
\text { baby } \\
(\mathrm{mo})\end{array}$} & $\mathrm{n}$ & \multicolumn{2}{|c|}{$\begin{array}{c}\text { Hb Concentration in } \\
\text { breastfeeding mothers }\end{array}$} & \multicolumn{2}{|c|}{$\begin{array}{r}\text { Hb Concentration in } \\
\text { infants }\end{array}$} \\
\cline { 3 - 6 } & & Mean & $\mathrm{Sd}$ & mean & $\mathrm{Sd}$ \\
\hline 0 & 17 & 12.388 & 1.273 & 13.471 & 1.715 \\
\hline 1 & 12 & 11.292 & 2.001 & 11.508 & 1.498 \\
\hline 2 & 21 & 12.024 & 1.497 & 11.476 & 2.110 \\
\hline 3 & 13 & 11.769 & 1.665 & 11.477 & 1.792 \\
\hline 4 & 18 & 11.556 & 1.399 & 10.300 & 1.598 \\
\hline 5 & 11 & 12.027 & 1.431 & 10.818 & 1.317 \\
\hline 6 & 8 & 12.200 & 1.782 & 10.587 & 1.399 \\
\hline
\end{tabular}

\section{B. Stunting in infant}

The infants ranged in age from 2.4 to 10.5 months of age, with fewer males than female, age distribution for both sexes; the sample included 
56 females and 44 males. The HAZ mean was negative (_0.359), and as many as 34 infants had an HAZ < _2 (stunting). Infants distribution for 0-6 months of age shown Table 3 .

TABLE III

STUNTING IN INFANTS 0-6 MONTH

\begin{tabular}{|c|c|c|c|c|c|}
\hline \multirow{2}{*}{$\begin{array}{c}\text { Age } \\
(\mathrm{mo})\end{array}$} & \multicolumn{2}{|c|}{ Stunting } & \multicolumn{2}{c|}{ Not Stunting } & Total \\
\cline { 2 - 6 } & $\mathrm{n}$ & $\%$ & $\mathrm{n}$ & $\%$ & \\
\hline 0 & 1 & 2.9 & 16 & 24.2 & 17 \\
\hline 1 & 1 & 2.9 & 11 & 16.7 & 12 \\
\hline 2 & 11 & 32.4 & 10 & 15.2 & 21 \\
\hline 3 & 4 & 11.8 & 9 & 13.6 & 13 \\
\hline 4 & 8 & 23.5 & 10 & 15.2 & 18 \\
\hline 5 & 6 & 17.6 & 5 & 7.6 & 11 \\
\hline 6 & 3 & 8.8 & 5 & 7.6 & 8 \\
\hline Total & 34 & 34.0 & 66 & 66.0 & 100 \\
\hline
\end{tabular}

Infants with stunting and anemia are only found in 6 infants of 34 infants with stunting (17.6\%), and then not associated between stunting in infants with anemia $(p=0.07)$. Distribution of stunting and anemia in 0-6 months of age infants are shown in Table 4.

TABLE IV

DISTRIBUTION OF STUNTING AND ANEMIA IN INFANTS

\begin{tabular}{|c|r|r|r|r|r|}
\hline \multirow{2}{*}{$\begin{array}{l}\text { Stunting in } \\
\text { Infant }\end{array}$} & \multicolumn{4}{|c|}{ Anemia in infant } & \multirow{2}{*}{$\mathrm{p}$} \\
\cline { 2 - 5 } & \multicolumn{2}{|c|}{ Anemia } & \multicolumn{2}{|c|}{ Not anemia } & \multirow{2}{*}{} \\
\hline & $\mathrm{n}$ & $\%$ & $\mathrm{n}$ & $\%$ & \\
\hline Stunting & 6 & 17.6 & 28 & 82.4 & \\
\hline Not stunting & 23 & 34.8 & 43 & 65.2 & \\
\hline & & & & & 0.073 \\
\hline
\end{tabular}

C. Associated between anemia in breastfeeding mothers with anemia and stunting in infant

Prevalence of anemia among breastfeeding mothers were more than non anemia mothers. Breastfeeding mothers anemia was not associated with anemia in infants $(\mathrm{p}=0.685>0.05)$, and not associated with stunting in infants $(\mathrm{p}=0.161>0.05)$. Table 5 shows the absence of that association between anemia in breastfeeding mother with anemia and stunting in infant.
TABLE V

RESULT OF CHI SQUARE TEST

\begin{tabular}{|c|c|c|c|c|c|}
\hline \multirow{2}{*}{ Infant } & \multicolumn{4}{|c|}{ Breastfeeding mothers } & \multirow{2}{*}{$\mathrm{p}$} \\
\cline { 2 - 5 } & \multicolumn{2}{|c|}{ Anemia } & \multicolumn{2}{c|}{ Not anemia } & \multirow{2}{*}{$\mathrm{N}$} \\
\hline & 21 & 40.4 & 13 & 27.1 & \\
\hline Stunting & 31 & 59.6 & 35 & 72.9 & \\
\hline Not stunting & & & & & 0.161 \\
\hline & 16 & 30.8 & 13 & 27.1 & \\
\hline Anemia & 36 & 69.2 & 35 & 72.9 & 0.685 \\
\hline Not anemia & 52 & 52.0 & 48 & 48.0 & \\
\hline Total & & & &
\end{tabular}

\section{IV.DISCUSSION}

The results of this study found that prevalence of anemia in breastfeeding mothers are more than $50 \%$. This prevalence is high, anemia is still widespread in Binjai City, Indonesia, and there is also a high risk of maternal mortality [10]. The prevalence of anemia is an important health indicator, then iron deficiency is thought to be the most common cause of anemia globally [11]. This study shows that anemia is an important public health problem in lactating women from Binjai City. Information about the use of haemoglobin concentration for diagnosing anaemia. It is a compilation of current World Health Organization (WHO) recommendations on the topic and summarizes the cut-offs for defining anaemia and its severity at the population level, as well as the chronology of their establishment [11].

The high prevalence of anemia in breastfeeding mothers in Kota Binjai, is similar to several other areas in various countries. Such as, the results of the study in Myanmar found that anemia during lactation was generally high. The overall prevalence was $60.3 \%$, which is similar with the reported rate $(61.1 \%)$ among women of reproductive age (15-45 years old), and with $20.3 \%$ of women having severe anemia [12]. Study in Somali found that anemia among lactating mothers was $43.8 \%$ and in the Afar region was $48.7 \%$ [13]. Study in India, the prevalence of lactation anemia was $81.7 \%$ in lactation up to 3 months [14].

Predictions from several factors associated with anemia prevalence of breastfeeding mothers from the results of several studies are mother and husband's education, nutrition status or maternal body mass index (BMI), currently working, wealth 
index, ever use of family planning, availability of antenatal services and iron tablets, maternal BMI, duration of breastfeeding, and maternal smoking [13]-[15]. Meanwhile, the study found that anemia breastfeeding mothers were more common in the age group 20-30 years $(78,8 \%)$, and with higher education $(65,4 \%)$, as well as with low family income $(65,4 \%<$ Rp. $1,700,000,-)$.

Anemia occurs at the last stage of iron deficiency. It doesn't start suddenly. Any negative impact to the breast, such as any the issues that cause to a reduced quality or volume of the breast milk, will cause side effects in the tolerance, productivity, and the quality of life [17]. An argument against iron supplementation is that the baby will not become anemic because the breast milk takes what the baby needs, leaving only the mother deficient [16].

The study found that the prevalence of anemia among infants 0-6 months is $29 \%$. Other studies in other countries in Asia even higher, such as in Philippines found that $42 \%$ children were anemic [3], and in Bhaktapur, Nepal there were $49 \%$ among infants 2-6 month [18]. The prevalence is almost similar to that of other studies that is $3.4 \%$ of infants at four months had iron deficiency anemia, and at six months of age $26.1 \%$ anemic, while iron deficiency anemia was present in $23.9 \%$ of the infants studied. Iron deficiency at six months of age was significantly correlated to growth velocity [19].

The results showed that haemoglobin levels in infants from newborn to the 6 months of life are decreasing, with an average of consecutive is 13.47 $\mathrm{g} / \mathrm{dl}, 11.51 \mathrm{~g} / \mathrm{dl}, 11.48 \mathrm{~g} / \mathrm{dl}, 10.30 \mathrm{gdl}, 10.82 \mathrm{~g} / \mathrm{dl}$, $10.59 \mathrm{~g} / \mathrm{dl}$. Meanwhile, according to a study Luoet. $\mathrm{Al}^{4}$ found that the level of haemoglobin in infants 611 months dropped sharply at age of 6-7 months and slowing down at the age of 8 months, and after the age of 9 months increased until the age of 11 months. The results showed that there was associated between anemia in breastfeeding mothers with anemia in infants $(p>0.05)$. This occurs because the iron reserves in the newborn's body exists and is independent of breast milk, and a few weeks after birth do not form new red blood cells.

After birth, red blood cell mass normally declines in response to an increase in the availability of oxygen and down regulation of erythropoietin. Red blood cell count decreases until oxygen delivery is inadequate for metabolic demand and erythropoietin production is stimulated again. In healthy term infants, the red blood cell nadir, a physiologic response to postnatal life and not a hematologic disorder, typically occurs at 8 to 12 weeks of life and at a haemoglobin level of 9-11 g/dl [20].

The results showed that the prevalence of stunting infants 0-6 monthsare up to $34 \%$. Among the anemic infants there is $17.6 \%$ of stunting, and anemia are not stunting infants have as many as $33.3 \%$. Anemia in infant not associated with stunting in infant aged 0-6 months $(p=0.073>0.05)$. Breastfeeding mothers anemia is not associated with stunting in infants $(\mathrm{p}=0.161>0.05)$. In breastfeeding anemic mothers, $40.4 \%$ of them had a infant stunting. In breastfeeding mothers that are not anemic, they mostly have no stunting in infants $(72.9 \%)$.

The results of this study differs from other studies which results of another study found that the older the age of the baby, the higher the prevalence of stunting. The prevalence of stunting in infants aged 2 months was $14.6 \%$, infants 6 months was $26.7 \%$ and $48.1 \%$ infants 12 months. Maternal nutritional status was associated with being underweight at both time-points but not with stunting ${ }^{21}$.Prevalence for stunting in infants aged $0-18$ months $39.58 \%$ and among infants with anemia, the prevalence rates of stunting were $47.46 \%$ [2].

Preventing anemia in breastfeeding mothers and their infants, and preventing stunting in children are important to be handled seriously, starting from the beginning of life, including pregnancy. Improving the health of mothers, newborns, and children world wife by USAID [22] has created a program of maternal and child survival. The program that has been created is an integrated nutrition program to reduce all forms of malnutrition. It include to improve the quality of dietary intake of mothers and children.

Interventions that can be done to prevent stunting and anemia in infants begins with improving the nutritional status of the mother during pregnancy. Improving the nutritional status of mothers during pregnancy can be through the implementation of a balanced nutrition and regular prenatal examination, in order to improve birth weight and increase the quantity and quality of breast milk. Medhin et al [21] stated that minimizes the infant nutritional 
differences in rural and urban by empowering women in rural areas to improve care practices with the optimum skills and increase the accessibility of health services. Investments in improving basic sanitary conditions and devise mechanisms to improve maternal malnutrition should be the focus for a short-term strategy. Other than that, exclusive breastfeeding protects infants from iron deficiency and iron deficiency anemia for the first four months of life.

\section{CONCLUSION}

As conclusion of this study there was no association between breast-feeding mothers with anemia in infants and stunting in infants. The problems of stunting in infants is higher than the problem of anemia in infantsand stunting that occurs in infants are not related to anemia in infants. However, there is no relationship between stunting that occurs in infants with anemia that occurs in infants. In the group of infants aged 4-6 months to lower their hemoglobin levels of a group of infants aged 1-3 months. The prevalence of stunting highest in infants aged two months.

\section{REFERENCES}

[1]. WHO. (2012) Proposed Global Targets for Maternal, Infant and Young Child. WHO Discussion Paper (6 February 2012). World Health Organization, at http://www. who.int/ about/copyright.

[2]. Yang, W.; Li, X. Li, Y;Zhang, S.; Liu, L.; Wang, X.; \& Li, W. (2012) Anemia, malnutrition and their correlations with socio-demographic characteristics and feeding practices among infants aged 0-18 months in rural areas of Shaanxi province in northwestern China: a cross-sectional study. BMC Public Health, 12:1127

[3]. Rohner, F; Woodruff, B.A.; Aaron, G.J.; Yakes, E.A. Lebanan M.A.O.; Rayco-Solon, P.; \& Saniel, O.P. (2013) Infant and young child feeding practices in urban Philippines and their associations with stunting, anemia, and deficiencies of iron and vitamin A. Food and Nutrition Bulletin, 34 (2): S17-34 (supplement), The United Nations University.

[4]. Luo, R.; Shi, Y.; Zhou, H,;Yue, A.; Zhang, L.; Sylvia, S.; Medina, A.; \& Rozelle, S. (2014) Anemia and Feeding Practices among Infants in Rural Shaanxi Province in China. Nutrients, 6, 5975-5991; doi: 10.3390/ nu6125975

[5]. Research and Development Agency for Health and MOH. Riskesdas 2013

[6]. Chaparro, C.; Oot, L.; \& Sethuraman, K. (2014) Indonesia Nutrition Profile. Washington, DC: FHI 360/FANTA.

[7]. Xiaoliang Y, Rongwei Y, Junchi Z, Lei J, Jianmeng L, Ren A. (2009) The relationship between anemia and physical development among children at the ages of 3-6 years in 21 counties of China. Wei Sheng Yan Jiu. 2009 Nov; 38 (6):688-91.

[8]. Rusli, U. (2009) Mengenal ASI eksklusif (Get to know exclusive breastfeeding). Jakarta: Puspa Swara.

[9]. Bilenko, N.; Yehiel, M.; Inbar, Y.; Gazala, E. (2007) The Association between Anemia in Infants, and Maternal Knowledge and Adherence to Iron Supplementation in Southern Israel. IMAJ, 9:521-24.

[10]. Allen, L.H. (2000) Anemia and iron deficiency: effects on pregnancy outcome. The American Journal of Clinical Nutrition. 2000;71(suppl):1280S-4S.
[11]. WHO. (2011) Haemoglobin concentrations for the diagnosis of anaemia and assessment of severity. VMNIS. Vitamin and Mineral Nutrition Information System, VMNIS1-6.

[12]. Zhao, A., Zhang, Y., Li, B., Wang, P., Li, J., Xue, Y., \&Gao, H. (2014) Prevalence of Anemia and Its Risk Factors Among Lactating Mothers in Myanmar. American Journal of Trop. Med. Hyg., 90(5), 2014, pp. $963-$ 967. doi:10.4269/ajtmh.13-0660.

[13]. Lakew, Y., Biadgilign, S., \& Haile, D. (2016). Anaemia prevalence and associated factors among lactating mothers in Ethiopia: evidence from the 2005 and 2011 demographic and health surveys. BMJ Open 2015; 5: e006001. doi:10.1136/bmjopen-2014-006001.

[14]. Agarwal, K.N., Gupta, V., \& Agarwal, S. (2013) Effect of maternal iron status on placenta, fetus and newborn. International Journal of Medicine and Medical Science. 5(9):391-395. DOI:10.5897/IJMMS09.233 from http://www. academicjournals.org / IJMMS

[15]. Zisovska, E., Lazarevska, L., Pehcevska, N., Tavcioska, G. (2010) Tobacco influence on the neonatal outcome. Italian Jurnal of Public Health. IJPH - Year 8, 7(3): 249-255.

[16]. Harding, S. (2013). Breast-Feeding \& an Anemic Mother. Available from http://www.livestrong.com.

[17]. Abbaspour, N., Hurrell, R., Kelishadi, R. (2014) Review on iron and its importance for human health. J Res Med Sci; 19: 164-174.

[18]. Chandyo, RK., Henjum, S., Ulak, M., Thorne-Lyman, AL,. Ulvik, RJ. Shrestha, PS., Locks, L., Fawzi, W., \& TA Strand, T.A. (2015) The prevalence of anemia and iron deficiency is more common in breastfed infants than their mothers in Bhaktapur, Nepal. European Journal of Clinical Nutrition (2015) 70: 456 - 462; doi:10.1038/ejcn.2015.199. published online 2 December 2015.

[19]. Marques, Rosa F.S.V., Taddei, José A.A.C., Lopez, Fábio A., Braga, Josefina A.P. (2014) Breastfeeding exclusively and iron deficiency anemia during the first 6 months of age. Revista da Associacao Medica Brasileira. 60(1):18-22. http://dx.doi.org/ 10.1590/1806 9282.60.01.006

[20]. Kett, J.C. (2012) Anemia in Infancy. In Brief. Pediatrics in Review 33(4):186-187 Available from http://pedsinreview. aappublications.org/.

[21]. Medhin, G., Hanlon, C., Dewey, M., Alem, A., Tesfaye, F., Worku, B., Tomlinson, M., Prince, M. (2010) Prevalence and predictors of under nutrition among infants aged six and twelve months in Butajira, Ethiopia: The P-MaMiE Birth Cohort. BMC Public Health 2010, 10:27. Available from http://www.biomedcentral.com/1471-2458/10/27.

[22]. USAID. (2016) Infant and Young Child Nutrition to Prevent Stunting. Maternal and Child Survival Program. Available from https://www.usaid.gov/maternal-and-child. 